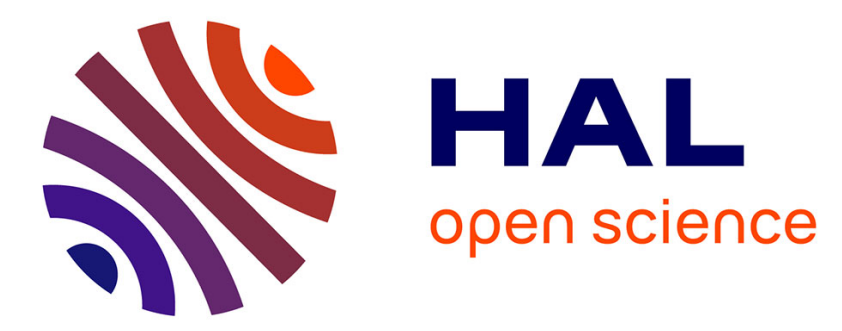

\title{
Deep neural networks for aberration compensation in digital holographic imaging of the retina
}

Julie Rivet, Guillaume Tochon, Serge Meimon, Michel Paques, Thierry

Géraud, Michaël Atlan

\section{To cite this version:}

Julie Rivet, Guillaume Tochon, Serge Meimon, Michel Paques, Thierry Géraud, et al.. Deep neural networks for aberration compensation in digital holographic imaging of the retina. Adaptive Optics and Wavefront Control for Biological Systems V, Feb 2019, San Francisco, CA, United States. pp.34, 10.1117/12.2509711 . hal-02176460

\section{HAL Id: hal-02176460 \\ https://hal.science/hal-02176460}

Submitted on 8 Jul 2019

HAL is a multi-disciplinary open access archive for the deposit and dissemination of scientific research documents, whether they are published or not. The documents may come from teaching and research institutions in France or abroad, or from public or private research centers.
L'archive ouverte pluridisciplinaire HAL, est destinée au dépôt et à la diffusion de documents scientifiques de niveau recherche, publiés ou non, émanant des établissements d'enseignement et de recherche français ou étrangers, des laboratoires publics ou privés. 


\title{
DEEP NEURAL NETWORKS FOR ABERRATIONS COMPENSATION IN DIGITAL HOLOGRAPHIC IMAGING OF THE RETINA
}

\author{
Julie Rivet ${ }^{1,2}$ Guillaume Tochon ${ }^{1}$ Serge Meimon ${ }^{3}$ Michel Paques ${ }^{4}$ Thierry Géraud $^{1}$ Michael Atlan ${ }^{2}$ \\ ${ }^{1}$ EPITA Research and Development Laboratory (LRDE) \\ ${ }^{2}$ ESPCI Paris, PSL Research University, Sorbonne Université, CNRS, Institut Langevin \\ ${ }^{3}$ ONERA - the French Aerospace Lab \\ ${ }^{4}$ Institut de la Vision, CIC 1423, INSERM UMR-S 968, CNRS, Sorbonne Université
}

\begin{abstract}
In computational imaging by digital holography, lateral resolution of retinal images is limited to about 20 microns by the aberrations of the eye. To overcome this limitation, the aberrations have to be canceled. Digital aberration compensation can be performed by post-processing of full-field digital holograms. Aberration compensation was demonstrated from wavefront measurement by reconstruction of digital holograms in subapertures [1], and by measurement of a guide star hologram [2]. Yet, these wavefront measurement methods have limited accuracy in practice. For holographic tomography of the human retina, image reconstruction was demonstrated by iterative digital aberration compensation, by minimization of the local entropy of speckle-averaged tomographic volumes [3]. However image-based aberration compensation is time-consuming, preventing real-time image rendering. We are investigating a new digital aberration compensation scheme with a deep neural network to circumvent the limitations of these aberrations correction methods. To train the network, 28.000 anonymized images of eye fundus from patients of the 15-20 hospital in Paris have been collected, and synthetic interferograms have been reconstructed digitally by simulating the propagation of eye fundus images recorded with standard cameras. With a U-Net architecture [4], we demonstrate defocus correction of these complex-valued synthetic interferograms. Other aberration orders will be corrected with the same method, to improve lateral resolution up to the diffraction limit in digital holographic imaging of the retina.The measurement of medical images can be hindered by blur and distortions caused by the physiological motion. Specially for retinal imaging, images are greatly affected by sharp movements of the eye.
\end{abstract}

Stabilization methods have been developed and applied to state-of-the-art retinal imaging modalities; here we intend to adapt them for coherent light detection schemes. In this paper, we demonstrate experimentally cross-correlation-based lateral and axial motion compensation in laser Doppler imaging and optical coherence tomography by digital holography. Our methods improve lateral and axial image resolution in those innovative instruments and allow a better visualization during motion.

\section{References}

[1] A. Kumar, W. Drexler, and R. A. Leitgeb, "Subaperture correlation based digital adaptive optics for full field optical coherence tomography," Optics Express, vol. 21, no. 9, pp. 10850-10866, 2013.

[2] C. Liu, X. Yu, and M. K. Kim, "Phase aberration correction by correlation in digital holographic adaptive optics," Applied Optics, vol. 52, no. 12, pp. 2940-2949, 2013.

[3] D. Hillmann, H. Spahr, C. Hain, H. Sudkamp, G. Franke, C. Pfäffle, C. Winter, and G. Hüttmann, "Aberration-free volumetric high-speed imaging of in vivo retina," Scientific Reports, vol. 6, p. 35209, 2016.

[4] O. Ronneberger, P. Fischer, and T. Brox, "U-net: Convolutional networks for biomedical image segmentation," in International Conference on Medical Image Computing and Computer-assisted Intervention. Springer, 2015, pp. 234-241. 